\title{
Thromboembolic events after aortic valve replacement in elderly patients with a Carpentier-Edwards Perimount pericardial bioprosthesis
}

\author{
W. Mistiaen, $\mathrm{MD}, \mathrm{PhD}^{\mathrm{a}}$ \\ Ph. Van Cauwelaert, $M D^{\mathrm{b}}$ \\ Ph. Muylaert, $M^{\mathrm{b}}$ \\ S. U. Sys, MD, PhD \\ F. Harrisson, $\mathrm{PhD}^{\mathrm{a}}$ \\ H. Bortier, $M D, P h D^{a}$
}

From the Laboratory for Human Anatomy and Embryology, ${ }^{\mathrm{a}}$ University of Antwerp, Antwerp, Belgium; the Department of Cardiovascular Surgery, ${ }^{\mathrm{b}}$ General Hospital Middelheim, Antwerp, Belgium; and the Department of Physiology, Biochemistry, and Biometrics, ${ }^{\mathrm{c}}$ Faculty of Veterinary Medicine, University of Ghent, Merelbeke, Belgium.

Received for publication June 19, 2003; revisions requested Oct 29, 2003; accepted for publication Nov 4, 2003.

Address for reprints: Wilhelm Mistiaen, $\mathrm{MD}, \mathrm{PhD}$, Laboratory for Human Anatomy, University of Antwerp, Groenenborgerlaan 171, 2020 Antwerp, Belgium (Email: mistiaen@ruca.ua.ac.be).

J Thorac Cardiovasc Surg 2004;127:1166-70 $0022-5223 / \$ 30.00$

Copyright (C) 2004 by The American Association for Thoracic Surgery

doi:10.1016/j.jtcvs.2003.11.010
Objectives: Thromboembolic events after aortic valve replacement with a bioprosthesis were the most frequently occurring complications in elderly patients. Whether this was valve related or dependent on other factors needed further exploration.

Methods: Five hundred patients with a median age of 73 years were followed retrospectively after aortic valve replacement with a pericardial prosthesis for occurrence of thromboembolism. Of these, 348 also underwent coronary artery bypass grafting. Twenty-five factors were investigated for their potential effect by using univariate and multivariate analysis.

Results: Univariate analysis revealed 6 significant factors: preoperative endocarditis $(P=.0001)$, preoperative cerebrovascular accident $(P=.002)$, use of postoperative warfarin sodium (Coumadin, DuPont Merck; $P=.006)$, arterial hypertension $(P=$ $.023)$, size of valve prosthesis of $27 \mathrm{~mm}$ or larger $(P=.023)$, and hospital thromboembolism $(P=.040)$. There was a trend toward increased fatal thromboembolism in patients without medication. With a multivariate analysis, 4 factors remained significant: preoperative cerebrovascular accident (risk ratio, 4.8; $P=$ .0016 ), warfarin sodium (risk ratio, 3.0; $P=.0028$ ), preoperative endocarditis (risk ratio, 5.6; $P=.006$ ), and hospital thromboembolism (risk ratio, $6.1 ; P=.016$ ). Hypertension had a borderline effect. Age, sex, diabetes, 4 coronary artery factors, 3 other valvular factors, atrial fibrillation, and carotid artery disease had no significant effect.

Conclusions: Some emboli seemed triggered by the valve prosthesis. A proper anticoagulant protocol but also a treatment of hypertension is important in the prevention of thromboembolism after aortic valve replacement with a bioprosthesis. We did not find a significant role of atrial fibrillation and carotid artery disease.

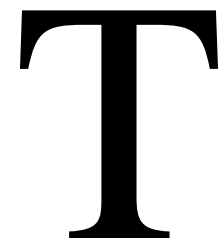

hromboembolic events after an aortic valve replacement with a bioprosthesis are a considerable part of the postoperative morbidity in elderly patients. Our objectives are identification of the risk factors for thromboembolism and recommendation of therapeutic measures in their prevention. Guidelines for reporting morbidity and mortality after cardiac valvular operations defined neurologic nonhemorrhagic deficits and peripheral arterial emboli as thromboembolic events until otherwise proved. ${ }^{1}$ This definition, however, seemed too large and could include thromboembolic events caused by other factors, such as hypertension, atrial fibrillation, other cardiac factors, and carotid artery disease. Thromboembolic events after aortic valve replacement with a bioprosthesis have been linked to the vascular 
TABLE 1. Univariate relationship between significant risk factors and occurrence of thromboembolism: the 5-year event-free rate for the factor present and absent and the $\boldsymbol{P}$ value as obtained from univariate analysis (Kaplan-Meier method)

\begin{tabular}{|c|c|c|c|c|c|c|c|c|}
\hline \multirow[b]{2}{*}{ Factor } & \multirow[b]{2}{*}{$\mathrm{TE} / \mathrm{n}$} & \multirow[b]{2}{*}{ Fatal } & \multirow[b]{2}{*}{ CVA } & \multirow[b]{2}{*}{ RIND } & \multirow[b]{2}{*}{ TIA } & \multicolumn{2}{|c|}{ 5-y event-free $\pm S E$} & \multirow[b]{2}{*}{$P$ value } \\
\hline & & & & & & Factor present & Factor absent & \\
\hline pCVA & $5 / 26$ & 2 & 2 & 0 & 0 & $0.79 \pm 0.09$ & $0.92 \pm 0.02$ & .002 \\
\hline WARF & $11 / 74$ & 2 & 8 & 0 & 1 & $0.81 \pm 0.06$ & $0.93 \pm 0.02$ & .006 \\
\hline AHT $(>140 / 90)$ & $32 / 349$ & 12 & 13 & 1 & 6 & $0.90 \pm 0.02$ & $0.97 \pm 0.02$ & .023 \\
\hline $27+$ & $11 / 85$ & 2 & 4 & 0 & 5 & $0.81 \pm 0.06$ & $0.94 \pm 0.01$ & .023 \\
\hline hTE & $2 / 9$ & 0 & 2 & 0 & 0 & $0.60 \pm 0.22$ & $0.92 \pm 0.02$ & .040 \\
\hline
\end{tabular}

$T E$, Number of patients with thromboembolism; $n$, number of patients with factor present; CVA, cerebrovascular accident; RIND, reversible ischemic neurologic deficit; TIA, transient ischemic attack; $p C V A$, preoperative cerebrovascular accident; WARF, postoperative use of warfarin sodium; $A H T$, arterial hypertension; $27+$, prosthesis size of $27 \mathrm{~mm}$ or larger; $h T E$, hospital thromboembolism.

status in earlier reports. ${ }^{2,3}$ This is of particular importance in elderly patients, in whom cardiac and vascular comorbidity is more common. In these patients carotid artery disease can be screened preoperatively by using a Doppler ultrasonographic technique. The role of anticoagulant medication in the occurrence of postoperative thromboembolic events in patients with chronic atrial fibrillation, preoperative cerebrovascular accidents (CVAs), and postoperative cardiac events also required exploration.

\section{Patients and Methods}

Five hundred consecutive patients receiving a Carpentier-Edwards Perimount pericardial valve in the aortic position were investigated retrospectively from 1986 through 2001 . In 152 patients only the aortic valve was replaced; the other 348 patients had a concomitant procedure, such as a coronary artery bypass grafting (CABG), a procedure on the ascending aorta $(n=27)$, or a mitral annuloplasty $(\mathrm{n}=13)$. Patients receiving valves in other positions or mechanical valves were excluded. All patients were operated on through a median sternotomy with standard cardiopulmonary bypass, hemodilution, and moderate general body hypothermia. Myocardial protection was obtained with orthograde and retrograde administration of a crystalloid cardioplegia solution and topical cooling with sludge ice.

Potential risk factors that could influence postoperative thromboembolic events were recorded. Previous endocarditis was considered a separate entity.

Warfarin sodium (Coumadin, DuPont Merck) was started on the day the thoracic drains were removed and continued for 3 months. It was continued only in the presence of other indications, mostly atrial fibrillation. Antiplatelet (160 mg aspirin daily) drugs were started in most other patients.

Follow-up was performed by using a questionnaire sent to cardiologists. Specific attention was given to neurologic deficits and peripheral arterial emboli. In all patients with a neurologic deficit, a computed axial tomography (CAT) scan was performed to exclude hemorrhage. The thromboembolic events were graded as transient ischemic attack (TIA; resolving within 30 minutes), reversible ischemic neurologic deficit (RIND; resolving within 24 hours), CVA (ie, with lasting sequelae), or fatal event.

Statistical analysis was performed in a univariate approach by using the Kaplan-Meier method to determine which of the poten- tial factors could be of significant prognostic importance. In the multivariate approach the Cox proportional hazards model was used to directly relate patient characteristics to the risk of a thromboembolic event. A $\chi^{2}$ analysis was performed to investigate the interrelation of categoric variables. Hospital thromboembolism is defined as the occurrence of the event in the first 30 days after the operation or in the same hospital period if this exceeded 30 days. Long-term thromboembolism is defined as the occurrence of this event after 30 days postoperatively or after discharge if the hospital stay exceeded 30 days.

\section{Results}

\section{Preoperative Data and Postoperative} Thromboembolism

There were 500 patients ( 271 male and 229 female patients) with a median age of 73 years (interquartile range, 71-77 years). They had a median ejection fraction of $65 \%$, (interquartile range, $51 \%-77 \%$ ). The mean follow-up was 4.2 years, with a total of 2022 patient-years. Nineteen patients died within the first 30 days, and a total of 139 , or $6.9 \%$ per patient-year, died during follow-up. During hospital stay, a thromboembolic event, confirmed by means of CAT scanning, occurred in 12 patients. In 3 patients this event was fatal. The event was a CVA in 5 patients, a RIND in 1 patient, and a TIA in 3 patients. None of the investigated factors had a significant effect on hospital thromboembolism. Of the 9 surviving patients, 2 had a long-term thromboembolism, and none received warfarin sodium.

During long-term follow-up, a thromboembolic event, also confirmed by means of CAT scanning, occurred in 36 patients, (ie, $1.8 \%$ per patient-year). In 12 patients these were fatal; in 15 patients these events were CVAs (in one as a result of a postoperative endocarditis, which was treated medically). The event was a RIND in 2 patients and a TIA in 6 patients. One patient had an event in the lower limbs.

\section{Individual Relationship of Patient Characteristics to Risk of Thromboembolism}

Table 1 shows the univariate analysis for the investigated factors, of which 5 had a significant effect on long-term 
TABLE 2. Univariate relationship between potential but nonsignificant risk factors and occurrence of thromboembolism: $\boldsymbol{P}$ value obtained from univariate analysis (KaplanMeier method)

\begin{tabular}{|c|c|c|c|}
\hline Factor & n & $\begin{array}{l}\text { Patients } \\
\text { with TE }\end{array}$ & $\begin{array}{c}P \\
\text { value }\end{array}$ \\
\hline \multicolumn{4}{|l|}{ Valvular } \\
\hline $\begin{array}{l}\text { Gradient across aortic } \\
\text { valve }>75 \mathrm{~mm} \mathrm{Hg}\end{array}$ & 246 & 21 & .19 \\
\hline $\begin{array}{l}\text { Aortic valve regurgitation of } \\
\text { grade II or more }\end{array}$ & 156 & 10 & .50 \\
\hline $\begin{array}{l}\text { Previously performed aortic } \\
\text { valve replacement }\end{array}$ & 15 & 2 & .35 \\
\hline \multicolumn{4}{|l|}{ Cardiac } \\
\hline $\begin{array}{l}\text { Crossclamping time }>75 \\
\min \end{array}$ & 115 & 9 & .28 \\
\hline Previously performed CABG & 35 & 3 & .29 \\
\hline $\begin{array}{l}\text { Implantation of } \geq 4 \\
\text { bypasses }\end{array}$ & 59 & 6 & .29 \\
\hline $\begin{array}{l}\text { Coronary artery disease on } \\
\text { angiography }\end{array}$ & 327 & 26 & .43 \\
\hline $\begin{array}{l}\text { Preoperative atrial } \\
\text { fibrillation }\end{array}$ & 83 & 7 & .56 \\
\hline $\begin{array}{l}\text { Preoperative 0-wave } \\
\text { myocardial infarction }\end{array}$ & 61 & 5 & .67 \\
\hline $\begin{array}{l}\text { Postoperative chronic atrial } \\
\text { fibrillation }\end{array}$ & 105 & 10 & .68 \\
\hline $\begin{array}{l}\text { Episode of atrial fibrillation } \\
\text { within the hospital }\end{array}$ & 189 & 12 & .81 \\
\hline Mitral annuloplasty & 13 & 1 & .98 \\
\hline \multicolumn{4}{|l|}{ Vascular } \\
\hline $\begin{array}{l}\text { Tailoring of the ascending } \\
\text { aorta }\end{array}$ & 27 & 2 & .87 \\
\hline $\begin{array}{l}\text { Carotid artery disease on } \\
\text { duplex scan }\end{array}$ & 53 & 3 & .88 \\
\hline $\begin{array}{l}\text { Postoperative use of } \\
\text { antiplatelet drugs }\end{array}$ & 220 & 12 & .10 \\
\hline \multicolumn{4}{|l|}{ General } \\
\hline Male sex & 271 & 23 & .18 \\
\hline Age over the median (73 y) & 250 & 23 & .19 \\
\hline $\begin{array}{l}\text { Carcinoma in preoperative } \\
\text { history }\end{array}$ & 53 & 4 & .50 \\
\hline Diabetes mellitus & 47 & 4 & .82 \\
\hline
\end{tabular}

$T E$, Thromboembolism; $n$, number of patients with factor present; $C A B G$, coronary artery bypass grafting.

thromboembolism. Preoperative endocarditis is considered a separate entity: 3 of the 8 patients had a thromboembolic event that was fatal, but none of the patients had signs of sepsis. The 5-year event-free rate for thromboembolism in patients with previous endocarditis was $0.28 \pm 0.23$ versus $0.92 \pm 0.02$ in patients without this condition $(P=.0001)$.

Preoperative CVA was significantly more common in patients with a positive duplex scan result $(11.3 \%$ vs $4.5 \%$, $P<.049)$. The severity of aortic valve stenosis was not different between patients with a positive duplex scan result and those with a negative duplex scan result: the median gradients across the valve were $75 \mathrm{~mm} \mathrm{Hg}(60-100 \mathrm{~mm} \mathrm{Hg}$ ) versus $74 \mathrm{~mm} \mathrm{Hg}(55-94 \mathrm{~mm} \mathrm{Hg})$, respectively. Seven patients with a positive duplex scan result underwent simultaneous carotid endarterectomy. They did not have any postoperative thromboembolic events.

The main reason for treatment with warfarin sodium was preoperative atrial fibrillation $(41.0 \%$ vs $9.6 \%, P<.001)$. Another reason was preoperative myocardial infarction (26.2\% vs $13.2 \%, P=.007)$. There was a trend toward postoperative use of warfarin sodium in patients with decreased left ventricular function $(19.2 \%$ vs $13.4 \%, P=$ $.096)$, preoperative CVA (23.3\% vs $14.0 \%, P=.10)$, and prior aortic valve replacement (33.3\% vs $14.2 \%, P=.109$ ). Patients older than 80 years took significantly less warfarin sodium (5.0\% vs $16.1 \%, P=.036)$. In 105 patients with postoperative chronic atrial fibrillation, 4 of 44 patients receiving warfarin sodium, 1 of 35 patients receiving acetylsalicylic acid, and 3 of 26 patients receiving no medication had an event. In 374 patients without atrial fibrillation, 7 of 30 patients receiving warfarin sodium, 12 of 185 patients receiving acetylsalicylic acid, and 10 of 159 patients receiving no medication had an event. There was a trend toward an increase in fatal events in patients taking no medication compared with in those taking acetylsalicylic acid $(8 / 206$ vs $2 / 220, P=.091)$.

Table 2 shows the nonsignificant parameters. Age greater than the median did not result in a significant increase in thromboembolism. Using age as a continuous variable, we found no significant difference $(P=.14)$.

\section{Simultaneous Relationship of Patient Characteristics to the Risk of Thromboembolism}

Table 3 shows the results of the multivariate analysis. Hospital thromboembolism carries the highest risk ratio. The effect of size of the valve prosthesis has become nonsignificant, and hypertension is borderline significant. If included, preoperative endocarditis is also a significant independent variable for thromboembolism. The other factors remain highly significant. Although atrial fibrillation was the main reason to prescribe warfarin sodium, an interaction term between those 2 factors did not result in a significant effect $(P=.29)$.

\section{Discussion}

Thromboembolism after aortic valve replacement was the most important valve-related postoperative complication. These events, however, could be associated with factors other than valve type..$^{2-5}$ Whatever the origin might be, thromboembolism after aortic valve replacement with a bioprosthesis was regarded as of more importance than structural failure. ${ }^{6}$ The annual rate of thromboembolic events in studies using several valve types ranged from $0.9 \%$ to $2.2 \%,{ }^{2-6}$ which was comparable with those in our series. 
Preoperative medically treated endocarditis in our patient population was considered a separate condition. High hospital mortality and annual rate of thromboembolism were found after valve replacement for endocarditis. ${ }^{7,8}$ One possible explanation is damage of the endocardium during infection, creating procoagulant conditions. Regular ultrasonographic control after valve replacement is considered necessary in these patients.

Other valvular factors, such as a valve size of $27 \mathrm{~mm}$ or larger, had a significant effect on postoperative thromboembolism only in a univariate analysis. Larger valve size was not identified as a risk factor in a previous series. ${ }^{2}$ Most series on valve size concerned the effect of the use of smaller valves and reported mainly on survival. ${ }^{9,10}$ Neither the type and severity of aortic valve disease ${ }^{2}$ nor rereplacement had significant effects on postoperative thromboembolism. $^{2}$

None of the investigated coronary factors had a significant influence on postoperative thromboembolism. Previous CABG could not be identified as a risk factor after aortic valve replacement with a Medtronic Hall valve. ${ }^{2}$ Nevertheless, crossclamping time and total bypass time ${ }^{11,12}$ and a recent myocardial infarction ${ }^{13}$ were previously identified as significant risk factors for postoperative stroke after CABG.

The role of atrial fibrillation in the occurrence of thromboembolism remains a matter for debate. No increase in thromboembolism was found in patients with a Medtronic Hall valve and preoperative or postoperative atrial fibrillation, ${ }^{2}$ yet the long-term risk for thromboembolism was considerably higher in patients with atrial fibrillation undergoing $\mathrm{CABG}^{13}$ or aortic valve replacement with a Hancock porcine bioprosthesis. ${ }^{14}$ In our and other ${ }^{14,15}$ patient groups, atrial fibrillation was the main reason for therapy with warfarin sodium. The effect of warfarin sodium in a series of patients after aortic valve replacement with a CarpentierEdwards pericardial bioprosthesis was studied earlier: an annual rate of thromboembolism of $0.8 \%$ with salicylic acid, of $1.5 \%$ with no treatment, and of $2.9 \%$ with warfarin sodium was observed in retrospect. ${ }^{16}$ This was considered as not significant, but a trend is clearly visible $(P=.07)$ and was comparable with the current results. Treatment with salicylic acid is to be recommended for patients with a pericardial valve, and the presence of atrial fibrillation requires more frequent ultrasonographic control for detection of intra-atrial thrombus formation.

In a previous analysis ${ }^{2}$ hypertension, smoking, and diabetes were identified as risk factors for ischemic cerebrovascular events, which were labeled as "arterial" and therefore unlikely to be altered by the intensity of anticoagulation. Moreover, use of peroral anticoagulants is considered as a serious condition with increased mortality. ${ }^{17}$

A history of preoperative CVA and the occurrence of hospital thromboembolism were also identified as signifi-
TABLE 3. Simultaneous relationship between the prognostic factors and the risk of thromboembolism obtained with the Cox proportional hazards analysis

\begin{tabular}{lcll}
\hline Factor & $\begin{array}{c}\text { Risk } \\
\text { ratio }\end{array}$ & $\mathbf{9 5 \%}$ Cl & $\begin{array}{c}\boldsymbol{P} \\
\text { value }\end{array}$ \\
\hline Cerebrovascular accident & 4.8 & $1.8-12.6$ & .0016 \\
Warfarin sodium & 3.0 & $1.5-6.3$ & .0028 \\
Hospital thromboembolism & 6.1 & $1.4-26.5$ & .016 \\
Arterial hypertension & 2.7 & $0.9-7.8$ & .063 \\
\hline
\end{tabular}

$\mathrm{Cl}$, Confidence interval.

cant independent factors after aortic valve replacement in octogenarians. ${ }^{18,19}$ One could link these risk factors with carotid artery disease. A negative duplex scan result of the carotid artery, which is considered a reliable diagnostic tool, ${ }^{20}$ does not exclude intracranial vasculopathy. Carotid lesions were not a significant factor for postoperative thromboembolism, although in another series asymptomatic patients with stenosis of the carotid artery of $80 \%$ had significantly more ischemic events. ${ }^{21}$ Therefore symptomatic patients with carotid artery stenosis benefit from endarterectomy of the carotid artery. No study directly showed the consequences of lesions of the carotid artery for neurologic thromboembolic events after aortic valve replacement, however.

Hypertension, another vascular factor, was previously identified as the most important predictor for postoperative stroke $^{11,12,22,23}$ and must be controlled tightly. Age in our population was not a significant factor, probably because our population was considerably older compared with those of other studies. ${ }^{2,24}$

Current and previous results indicate clearly that the origins of thromboembolism after aortic valve replacement, with or without association of a CABG, are multiple. After valve replacement, regions of relative stasis and of flow with high velocity in varying degree were demonstrated in all prostheses. ${ }^{25}$ A postulated mechanism for thromboembolism is platelet activation induced by shear stress, with adherence to the valve prosthesis and to the atheromatous plaques on vessel walls. Subsequent embolization to the cerebral blood flow could be responsible for thromboembolic events, even with small carotid lesions. It seems that the definition of thromboembolic events offered in the guidelines ${ }^{1}$ remains partially valid. Atrial fibrillation and use of warfarin sodium, which targets the coagulation system, ${ }^{2}$ do not play a role in this hypothetic sequence of events, which explains partly our counterintuitive results. A trend toward reduction of fatal thromboembolic events is observed with acetylsalicylic acid. Moreover, we could assume that small cerebral emboli go unnoticed. Warfarin sodium could facilitate hemorrhagic transformation, which could be held responsible for these neurologic events be- 
coming symptomatic. This chain of events will probably remain hypothetical because it is not feasible to perform regular computed tomographic scans for every patient with a pericardial valve to detect all emboli. Nevertheless, implantation of aortic valve prostheses can be considered a minor contributor to cerebrovascular events.

We therefore recommend that use of acetylsalicylic acid should be promoted strongly, especially in patients with larger valve size or previously treated endocarditis. The long-term use of warfarin sodium after aortic valve replacement with a bioprosthesis could be cautiously considered in elderly patients with atrial fibrillation and previous thromboembolic events. These patients should receive regular ultrasonographic control. Hypertension should be controlled tightly. If a tissue valve for a certain patient is indicated, a Carpentier-Edwards pericardial valve can be recommended.

\section{References}

1. Edmunds LH Jr, Clark RE, Cohn LH, et al. Guidelines for reporting morbidity and mortality after cardiac valvular operations. $J$ Thorac Cardiovasc Surg. 1996;112:708-11.

2. Butchart EG, Moreno de la Santa P, Rooney SJ, et al. Arterial risk factors and ischaemic cerebrovascular events after aortic valve replacement. J Heart Valve Dis. 1995;4:1-8.

3. Aupart MR, Sirinelli AL, Diemont FF, et al. The last generation of pericardial valves in the aortic position: ten-year follow-up in 589 patients. Ann Thorac Surg. 1996;61:615-20.

4. Torka MC, Salefsky BE, Hacker RW. Intermediate clinical results after aortic valve replacement with the Carpentier-Edwards pericardial bioprosthesis. Ann Thorac Surg. 1995;60(suppl):S311-5.

5. Edwards TJ, Livesey SA, Simpson IA, et al. Biological valves beyond fifteen years: the Wessex experience. Ann Thorac Surg. 1995; 60(suppl):S211-5.

6. Jamieson WRE, Munro AI, Miyagishima RT. Carpentier-Edwards standard porcine bioprosthesis: clinical performance to seventeen years. Ann Thorac Surg. 1995;60:999-1007.

7. Dodge A, Hurni M, Ruchat P, et al. Surgery in native valve endocarditis: indications, results and risk factors. Eur J Cardiothorac Surg. 1995;9:330-4.

8. Grunenfelder J, Akins CW, Hilgenberg AD, et al. Long-term results and determinants of mortality after surgery for native and prosthetic valve endocarditis. J Heart Valve Dis. 2001;10:694-702.
9. Medalion B, Lytle BW, McCarthy PM, et al. Aortic valve replacement for octogenarians: are small valves bad? Ann Thorac Surg. 1999;67: 1543-4.

10. Adams DH, Chen RH, Kadner A, et al. Impact of small prosthetic valve size on operative mortality in elderly patients after aortic valve replacement for aortic stenosis: does gender matter? J Thorac Cardiovasc Surg. 1999;118:815-22.

11. Cernaianu AC, Vassilidze TV, Flum DR, et al. Predictors of stroke after cardiac surgery. J Card Surg. 1995; 10:334-9.

12. Attum AA, Girardet R, Barbie R, et al. Risks of cerebrovascular events related to open heart surgery. J Ky Med Assoc. 1998;96(8):290-5.

13. Stamou SC, Hill PC, Dangas G, et al. Stroke after coronary artery bypass: incidence, predictors and clinical outcome. Stroke. 2001;32: 1508-13.

14. Cohn LH, Collins JJ Jr, Rizzo RJ, et al. Twenty-year follow-up of the Hancock modified orifice porcine aortic valve. Ann Thorac Surg. 1998;66(suppl 6):S30-4.

15. Helft G, Tabone X, Georges JL, et al. Bioprosthetic valve replacement in elderly. Eur Heart J. 1995;16:529-33.

16. Blair KL, Hatton AC, White D, et al. Comparison of anticoagulation regimens after Carpentier-Edwards aortic or mitral valve. Circulation. 1994;90(suppl II):II214-9.

17. Pellerin M, Mihaileanu S, Couëtil JP, et al. Carpentier-Edwards bioprosthesis in aortic position: long-term follow-up: 1980 to 1994. Ann Thorac Surg. 1995;60(suppl):S292-6.

18. Debetaz LF, Ruchat P, Hurni M, et al. St Jude Medical valve prosthesis: an analysis of long-term outcome and prognostic factors. J Thorac Cardiovasc Surg. 1997;113:134-48.

19. Kvidal P, Bergstrom R, Malm T, et al. Long-term follow-up of morbidity and mortality after aortic valve replacement with a mechanical valve prosthesis. Eur Heart J. 2000;21:1099-111.

20. Orgles CS, Chakraverty S, Gopichandran TD. Carotid stenosis in the real world: can Doppler ultrasound replace angiography in a district hospital setting? Clin Radiol. 1999;54:655-8.

21. Shanik GD, Moore JD, Leahy A, et al. Asymptomatic carotid lesion, a benign lesion? Eur J Vasc Surg. 1992;6:10-5.

22. Lund O, Magnussen K, Knudsen M, et al. The potential for normal long term survival and morbidity rates after aortic valve replacement for aortic stenosis. J Heart Valve Dis. 1996;5:258-67.

23. Elayda MA, Hall RJ, Reul RM, et al. Aortic valve replacement in patients of 80 years and older. Operative risks and long-term results. Circulation. 1993;88(suppl II):II11-6.

24. Glower DD, Landolfo KP, Cheruvu S, et al. Determinants of 15 year outcome with 1,119 standard Carpentier-Edwards porcine valves. Ann Thorac Surg. 1998;66(suppl 6):S44-8.

25. Ruggeri ZM. Mechanisms of shear-induced platelet adhesion and aggregation. Thromb Haemost. 1993;70:119-23. 